\title{
Benefits of sexual practice during pregnancy: myth or reality? Comparative study and outcome of childbirth in Douala (Cameroon)
}

\author{
Henri Essome ${ }^{1,2 *}$, Thomas O. Egbe ${ }^{3}$, Theophile N. Nana ${ }^{3}$, Valere K. Mve ${ }^{4}$, \\ Merlin Boten ${ }^{2}$, Grace T. Tocki ${ }^{2}$, Gregory E. Halle ${ }^{3}$
}

\author{
${ }^{1}$ Faculty of Medicine and Pharmaceutical Sciences of Douala, University of Douala, Cameroon \\ ${ }^{2}$ Laquintinie Hospital, Douala, Cameroon \\ ${ }^{3}$ Faculty of Health Sciences, University of Buea, Cameroon \\ ${ }^{4}$ Faculty of Medicine and Biomedical Sciences, University of Yaoundel, Cameroon
}

Received: 03 July 2020

Revised: 09 September 2020

Accepted: 10 September 2020

\section{*Correspondence: \\ Dr. Henri Essome, \\ E-mail: essometocky@yahoo.com}

Copyright: ( ) the author(s), publisher and licensee Medip Academy. This is an open-access article distributed under the terms of the Creative Commons Attribution Non-Commercial License, which permits unrestricted non-commercial use, distribution, and reproduction in any medium, provided the original work is properly cited.

\section{ABSTRACT}

Background: Pregnancy is the term used to describe the period in which a foetus develops in the uterus and lasts 40 weeks measured from the last menstrual period. Anatomic and physiologic changes in pregnant women usually make couples to change their emotional and sexual activities that may impact childbirth. There are few studies in our setting that describe the roles of sexual practice during pregnancy and maternal-foetal outcomes of childbirth.

Objective of this study aimed at assessing the benefits of sexual practice during pregnancy in a target population and to assess the outcome.

Methods: We carried out a comparative cross-sectional study from February 2018 to May 2018, at the maternity of Laquintinie Hospital in Douala. Socio-demographic, obstetric, sexual history in pregnancy, birth and neonatal data were collected using a structured questionnaire. Univariate and multivariate analyses were conducted at a $95 \%$ confidence interval.

Results: A total of 300 respondents completed study and $69.6 \%$ were favourable to sexual intercourse during pregnancy. Induction or augmentation of labour was common in the unfavourable group [OR: 2.52 (1.53-4.15); $\mathrm{p}=0.004]$. Almost one in two participants gave birth by caesarean section and the indications for caesarean section were similar in both groups. Participants without sexual intercourse in pregnancy had a 9-fold increased risk of perineal tears [OR: 8.99 (4.02-10.1); $\mathrm{p}=0.001$ ] and 5.4-fold risk of cervical tears [OR: 5.44 (2.44-8.73); $\mathrm{p}=0.0001]$.

Conclusions: Sexual practice in pregnancy appears to be protective against excessive use of oxytocin, perineal and cervical tears.

Keywords: Childbirth, Outcome, Pregnancy, Prejudice, Sexual practice

\section{INTRODUCTION}

Pregnancy is the set of phenomena that take place between fertilization and childbirth during which the embryo and then the foetus develop in the uterus. ${ }^{1}$ During this period, the body modifications and the emerging identity changes will lead the woman and her partner to redefine their emotional and sexual relationship., ${ }^{2,3}$ Sexual practice during pregnancy is greatly influenced by ethnic, cultural and religious beliefs. ${ }^{3}$

Some pregnant women and their partners are most often afraid of damaging their foetus, having a miscarriage or even having a premature birth. ${ }^{2}$ This is how we notice a decrease in libido, a refusal of coitus. ${ }^{4}$ When asked if sexual practice is permitted during pregnancy and if there 
would be no consequences that would result in order to carry it through, several studies have been conducted around the world. ${ }^{5}$

In Iran, a study by Kafaei et al found that sexual intercourse or contact with sperm did not affect the type of delivery (caesarean or vaginal delivery). ${ }^{6}$ Torkestani et al in 2012, still conducted in Iran, a study which revealed that $39.45 \%$ of women were afraid of having an abortion if they had sex during pregnancy. ${ }^{7}$ In India, a study carried out by Chhabra and Verma reveals that $30.61 \%$ of sexually active women have started premature labour. ${ }^{8}$ Tan et al in Malaysia found in a study in 2006 that long-term sexual relations were influenced by the perception of ethnic beliefs. ${ }^{9}$ In Brazil, the Txikaos Indians believe that without sperm, there would be an abortion because the child is no longer viable. ${ }^{10}$ In the Peruvian Andes, intercourse is stopped after 7 months for fear that the penis may touch the child and flatten his nose. ${ }^{10}$

In certain ethnic groups in Africa, sexual intercourse is essential for the proper development of the foetus. For example, in Zaire, Burkina Faso, Côte d'Ivoire and Ghana, the foetus would need seminal fluid or "growth milk" to feed and form. ${ }^{10}$ In Nigeria penetration helps prepare for labour while continually keeping the genital tract open. ${ }^{10}$ On the other hand, in certain ethnic groups, sexual intercourse is stopped during pregnancy: in Gabon after 5 months of pregnancy, sexual intercourse makes the child dirty at birth; after 8 months the sperm could even cause fever in the foetus. ${ }^{10} \mathrm{~A}$ study by Dao et al in Burkina Faso found that $92.6 \%$ of women thought it was possible to have sex during pregnancy and $63.2 \%$ of them thought that there would be no consequences for the unborn child. ${ }^{11}$ In Nigeria, Orji et al found that sexual desire remained unchanged in $60 \%$ of pregnant women and that the frequency decreased in $64 \%$ of cases. ${ }^{12}$ Andima still in Nigeria finds that $44.3 \%$ think that sexual intercourse during pregnancy widens the vagina and facilitates labour and for $30.2 \%$ of his sample there would be an abortion at the start of pregnancy. ${ }^{13}$

In Cameroon, Foumane et al found that sexually active women had a normal labour and a lower rate of caesarean section. ${ }^{14}$

From previous studies, it is clear that sexual practice during pregnancy is a subject of controversy, with heterogeneous and divergent data according to the geographical area. We therefore deemed it useful to examine this theme for the purposes of clarification and scientific documentation on the gestation of Douala.

\section{METHODS}

This was a cross-sectional comparative study carried out at the maternity unit of Laquintinie hospital, Douala (LHD) for a duration of 4 months from February 2018 to May 2018 with two arms formed in relation to the prejudices favorable or not to sexual practice during the pregnancy.

\section{Study population}

\section{Target population}

It was made up of women received in postpartum consultation or staying after childbirth at the Laquintinie hospital maternity unit.

\section{Inclusion criteria}

Included were those who had unprotected sex during their pregnancies, who expressed agreement to participate in the study and had a workable obstetric record.

\section{Exclusion criteria}

Excluded were all those participants who did not adhere to the study as much as those whose obstetric record was unusable, as well as those who had protected sex after their fertilization.

\section{Sampling}

We carried out a non-exhaustive consecutive type sampling.

\section{Data collection equipment and procedure}

The data were collected using a pre-tested questionnaire as well as the use of obstetric records and prenatal follow-up books. The variables of interest for this study are mentioned below.

\section{Socio-demographic}

Age, type of occupation, religion, region of origin, marital status, area of residence, and level of education

\section{Obstetrics}

Pregnancy, parity, and histories of previous pregnancies.

\section{Sexual practice during pregnancy}

Prejudices, the frequency of sexual intercourse depending on the term of the pregnancy, and complications linked to sexual practice during pregnancy.

\section{Data on delivery}

Route of delivery, foetal presentation, dilation on admission, station on admission, condition of the membranes, colour of the amniotic fluid (AF) at rupture, use oxytocin (OCT), mode of onset, and maternal complications during childbirth. 


\section{Data on the characteristics of the newborn at birth}

Apgar score, pathologies detected at birth, and foetal death.

\section{Statistical analysis}

The data were entered and analyzed by software Epi info version 3.5.1, Microsoft excel 2013 and statistical package for the social sciences (SPSS) version 20.0. The variables were compared using the Fisher test. The mean values were expressed with their $95 \%$ confidence interval and the threshold for statistical significance was $\mathrm{p}<0.05$. Univariate and multivariate analyses checked for associations.

\section{Ethical considerations}

Respect for medical ethics and deontology is an integral part of this study, which strives to respect the following aspects: ethical clearance has been obtained from the institutional authority of the University of Douala, authorization from the General Director of the LHD to set up the study has been obtained, and each woman received an information and consent sheet which was sent to her explained with signature for those who joined the study.

\section{RESULTS}

At the end of the data collection, we recruited 320 nannies and new-borns; we excluded 20 of them who did not consent to the study and enrolled 300 including 207 (69\%) having prejudices favorable to sexual activity in pregnancy and $93(31 \%)$ reluctant to practice sexual activity during pregnancy, therefore constituting two matched arms for this study. The turnout was $93.75 \%$ (Figure 1).

\section{Socio-demographic characteristics of the study population}

In our series, the age varied between 15-45 years with an average of $27.27 \pm 6.2$ years; the majority age group was (25-30) with no significant difference in the two groups $(\mathrm{p}>0.05)$. The respondents of the two groups were mostly single and of secondary education but without any statistical difference observed between them [OR: 0.66 (0.39-1.11); $\mathrm{p}=0.342$ ] [OR: 0.4 (02- 0.81); $\mathrm{p}=0.750$ ] (Table 1).

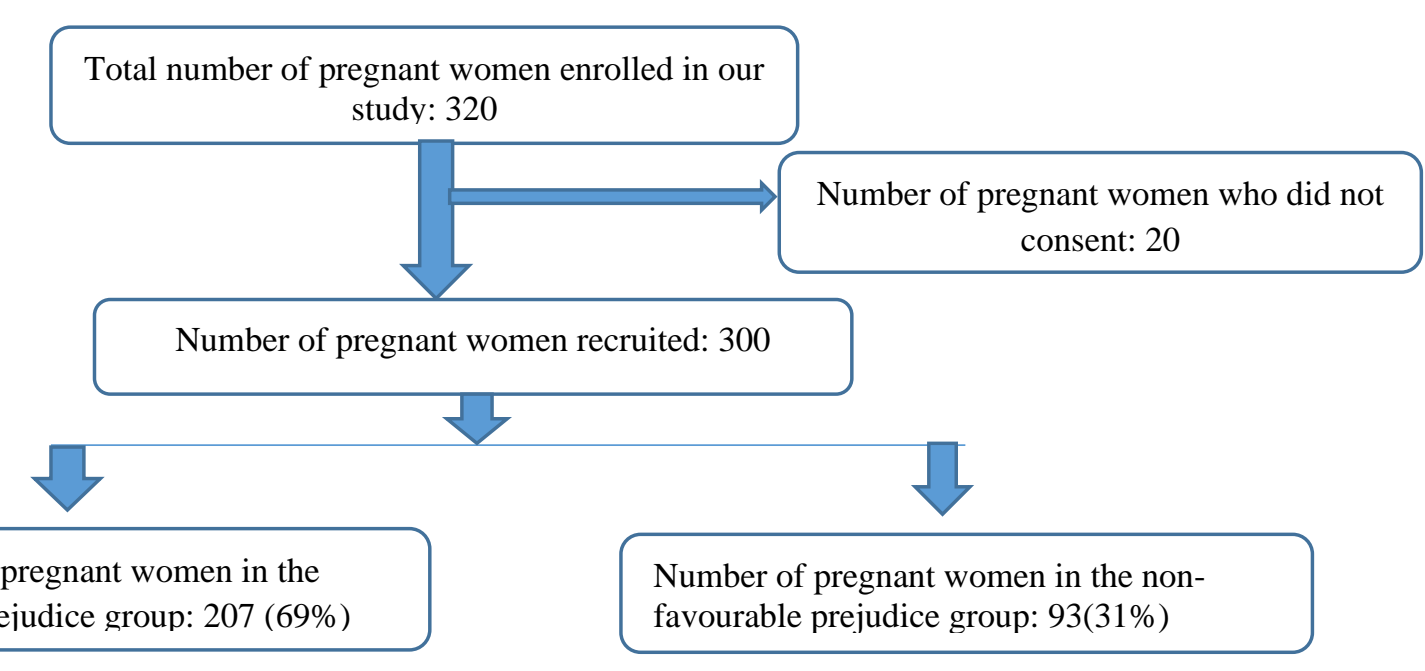

Figure 1: The stages of recruiting pregnant women for the study.

Table 1: Distribution of the target population according to age group, occupation, region of origin, religion, marital status, level of education.

\begin{tabular}{|c|c|c|c|c|}
\hline Variables & FP n=207, N (\%) & NFP n=93, N (\%) & OR $(95 \%$ CI $)$ & P value \\
\hline \multicolumn{5}{|l|}{ Age (years) } \\
\hline $15-20$ & $22(10.63)$ & $15(16.13)$ & $0.73(0.32-1.67)$ & 0.210 \\
\hline $20-25$ & $46(22.22)$ & $23(24.73)$ & $1.36(0.6-3.1)$ & 0.675 \\
\hline $25-30$ & $69(33.33)$ & $28(30.11)$ & $1.68(0.76-3.7)$ & 0.650 \\
\hline $30-35$ & $45(21.74)$ & $18(19.35)$ & $1.7(0.72-3.99)$ & 0.677 \\
\hline $35-40$ & $17(8.21)$ & $6(6.45)$ & $1.93(0.62-6.03)$ & 0.610 \\
\hline $40-45$ & $8(3.86)$ & $3(3.23)$ & $1.82(0.42-7.89)$ & 0.789 \\
\hline \multicolumn{5}{|l|}{ Occupation } \\
\hline House-wife & $73(35.27)$ & $30(32.26)$ & $1.4(0.76-2.58)$ & 0.681 \\
\hline Scolarised & $54(26.09)$ & $31(33.33)$ & $0.72(0.39-1.33)$ & 0.275 \\
\hline Civil servant & $31(14.98)$ & $14(15.05)$ & $0.91(0.43-1.94)$ & 0.987 \\
\hline
\end{tabular}

Continued. 


\begin{tabular}{|c|c|c|c|c|}
\hline Variables & $\mathrm{FP} n=207, \mathrm{~N}(\%)$ & $\mathrm{NFP} n=93, \mathrm{~N}(\%)$ & OR (95\% CI) & P value \\
\hline Others & $49(23.67)$ & $18(19.35)$ & $1.12(0.56-2.23)$ & 0.464 \\
\hline \multicolumn{5}{|l|}{ Region of origin } \\
\hline Centre & $21(10.14)$ & $19(20.43)$ & $1.33(0.4-4.39)$ & 0.240 \\
\hline East & $7(3.38)$ & $8(8.60)$ & $0.79(0.29-2.59)$ & 0.061 \\
\hline Far north & $5(2.42)$ & $2(2.15)$ & $2.86(0.42-9.67)$ & 0.890 \\
\hline Littoral & $31(14.98)$ & $21(22.58)$ & $1.69(0.53-5.37)$ & 0.143 \\
\hline North & $3(1.45)$ & $5(5.38)$ & $0.69(0.12-3.99)$ & 0.054 \\
\hline North-west & $13(6.28)$ & $1(1.08)$ & $1.99(1.53-4.45)$ & 0.054 \\
\hline West & $116(56.04)$ & $28(30.11)$ & $4.73(1.58-13.14)$ & 0.003 \\
\hline South & $6(2.90)$ & $7(7.53)$ & $0.98(0.22-4.35)$ & 0.075 \\
\hline South-west & $5(2.42)$ & $2(2.15)$ & $2.86(0.82-9.05)$ & 0.890 \\
\hline \multicolumn{5}{|l|}{ Religion } \\
\hline Animist & $1(0.48)$ & $2(2.15)$ & $0.16(0.01-1.3)$ & 0.182 \\
\hline Others & $17(8.21)$ & $13(13.98)$ & $0.41(0.18-0.91)$ & 0.144 \\
\hline Catholic & $135(65.22)$ & $42(45.16)$ & $2.46(1.1-5.48)$ & 0.036 \\
\hline Muslim & $7(3.38)$ & $6(6.45)$ & $0.89(0.24-3.29)$ & 0.237 \\
\hline Presbyterian & $44(21.26)$ & $23(24.73)$ & $0.6(0.33-1.11)$ & 0.555 \\
\hline Jehovah witness & $3(1.45)$ & $7(7.53)$ & $0.39(0.13-0.45)$ & 0.069 \\
\hline \multicolumn{5}{|l|}{ Marital status } \\
\hline Single & $121(58.45)$ & $63(67.74)$ & $0.66(0.39-1.11)$ & 0.342 \\
\hline Married & $85(41.06)$ & $29(31.18)$ & $1.53(0.91-2.57)$ & 0.199 \\
\hline Widow (er) & $1(0.48)$ & $1(1.08)$ & $0.34(0.02-4.99)$ & 0.561 \\
\hline \multicolumn{5}{|l|}{ Level of education } \\
\hline Primary & $19(9.18)$ & $20(21.51)$ & $2.47(1.22-5.01)$ & 0.006 \\
\hline Secondary & $122(58.94)$ & $52(55.91)$ & $0.4(0.2-0.81)$ & 0.750 \\
\hline Higher education & $63(30.43)$ & $18(19.35)$ & $1.49(0.8-2.76)$ & 0.088 \\
\hline None & $3(1.45)$ & $3(3.23)$ & $0.43(0.08-2.2)$ & 0.314 \\
\hline
\end{tabular}

$\mathrm{FP}=$ favorable prejudice, $\mathrm{NFP}=$ non favorable prejudice, $\mathrm{N}=$ total number, $\mathrm{n}=$ category number, $\%=$ percentage, $\mathrm{OR}=\mathrm{odd}$ ratio,

$\mathrm{CI}=$ confidence interval

\section{Obstetric characteristics}

Our respondents were multi-gravid and multiparous for the most part in the two groups but without statistical difference for these variables $(p>0.05)$. The majority gestational age in our series fell within the period of term (37 and 40 weeks) and 16 pregnancies (7.72\%) ended preterm in the sexually favorable against $9(9.67 \%)$ in the paired group (Table 2). For favorable prejudice (FP) group: minimum $=1 ;$ maximum $=9 ;$ mean $=2.6$; standard deviation $(\mathrm{SD})=1.54$. For non favorable prejudice (NFP) group: minimum $=1 ;$ maximum $=10 ;$ mean=2.41; $\mathrm{SD}=1.49$.

The majority of pregnant women were between their second and third gestation. In the group of women with FP, a woman had on average 2.6 pregnancies \pm 1.54 , a minimum of one pregnancy and a maximum of 9 pregnancies against an average of $2.41 \pm 1.49$, a minimum of a pregnancy, and a maximum of 10 pregnancies in the group of women with NFP.

\section{Sexual characteristics}

The data on sexual practice in pregnancy were heterogeneous and varied according to the term and the group.
Before the 28th week of amenorrhea (WA), the respondents in the group with NFP mainly had one coitus per week as opposed to the group with FP which had an admitted frequency of 2 to 3 coitus per week but without significant statistical impact [OR: 2, 94 (1.57-5.52) $(\mathrm{p}=0.086]$ (Table 3). The coital frequency of the gestational period from $28 \mathrm{WA}$ to $36+6 \mathrm{WA}$ was identical to the previous one in the two groups with however a statistically significant difference from the FP [OR: 5.1 (2.42-10.75) $\quad(\mathrm{p}=0.004] \quad$ (Table 3). Eventually, sexual practice suffered a decline and $80.6 \%$ (167) of our series (207) had sexual intercourse per week (Table 3).

\section{Parturition characteristics}

Induction was artificial (balloon placement and lower pole detachment) in the majority of cases in our series in the order of $69.6 \%$ (209 cases) with significant use of oxytocin in the group not favorable to sexual practice during pregnancy [OR: $2.52(1.53-4.15) \mathrm{p}=0.004]$. On admission, the majority of pregnant women $(62.66 \%)$ in both groups were in the active phase. The mean dilation in women with FP was $4.23 \pm 2.5 \mathrm{~cm}$ compared to $4.49 \pm 2.49 \mathrm{~cm}$ in those who were reluctant to sexual activity during pregnancy; the fetal station was predominantly $\geq 4$ on admission in the two groups in our series. The membranes were 
predominantly intact on admission in the two paired groups (Table 4); almost one in two pregnant women in our series gave birth by caesarean section and the indications for caesarean section were invariably the same in both arms (Table 5). However, we found a significant association between maternal complications and reluctance to sexual activity; this increased the risk of perineal tears by nine times [OR: 8.99 (4.02-10.1) $\mathrm{p}=0.001]$ and more than five times to cervical tears [OR: $5.44(2.44-8.73) \mathrm{p}=0.0001)$; cases of uterine rupture were twice as many as in the opposite group and six times as many cases of postpartum hemorrhage but without statistically significant impact (Table 6).

\section{Characteristics of the new-born}

We found no statistically significant difference in fetal well-being in the two groups (Apgar score, malformation and death) (Tables 7-9).

Table 2: Distribution of the target population according to parity and gestational age.

\begin{tabular}{|c|c|c|c|c|}
\hline Variables & FP n=207, N (\%) & NFP $n=93, \mathbf{N}(\%)$ & OR $(95 \% \mathrm{CI})$ & $P$ value \\
\hline \multicolumn{5}{|l|}{ Parity } \\
\hline Primiparous & $78(37.68)$ & $34(36.56)$ & $1.05(0.63-1.74)$ & 0.883 \\
\hline Multiparous & $129(62.32)$ & $59(63.44)$ & $0.95(0.57-1.7)$ & 0.910 \\
\hline \multicolumn{5}{|c|}{ Gestational age (GA) } \\
\hline $28-33$ & $5(2.42)$ & $2(2.15)$ & $1.59(0.24-9.57)$ & 0.890 \\
\hline $33-36$ & $11(5.32)$ & $7(7.53)$ & $0.63(0.09-4.19)$ & 0.469 \\
\hline $37-40$ & $149(71.98)$ & $63(67.74)$ & $1.5(0.50-4.07)$ & 0.686 \\
\hline Above 41 & $42(20.28)$ & $21(22.58)$ & $1.27(0.43-3.72)$ & 0.689 \\
\hline
\end{tabular}

$\mathrm{FP}=$ favorable prejudice, $\mathrm{NFP}=$ non favorable prejudice, $\mathrm{N}=$ total number, $\mathrm{n}=$ category number, $\%=$ percentage, $\mathrm{OR}=\mathrm{odd}$ ratio, $\mathrm{CI}=$ confidence interval

Table 3: Distribution of the target population according to sexual practice during pregnancy before 28 WA, between 28 and $37 \mathrm{WA}$ and at $37 \mathrm{WA}$.

\begin{tabular}{|c|c|c|c|c|}
\hline Variables & FP n=207, N (\%) & NFP $n=55, \mathbf{N}(\%)$ & OR $(95 \% \mathrm{CI})$ & P value \\
\hline \multicolumn{5}{|c|}{ Before 28 WA } \\
\hline $1 * /$ week & $76(36.7)$ & $38(69.1)$ & $0.34(0.18-0.64)$ & 0.001 \\
\hline $2-3 * /$ week & $100(48.3)$ & $17(30.9)$ & $2.94(1.57-5.52)$ & 0.086 \\
\hline $4^{*}$ and above & $31(15.0)$ & - & - & - \\
\hline Total & $207(100.0)$ & $55(100.0)$ & - & - \\
\hline \multicolumn{5}{|c|}{ Between 28 WA and 37 WA } \\
\hline $1 * /$ week & $83(40.1)$ & $45(81.8)$ & $0.20(0.1-0.42)$ & 0.0001 \\
\hline $2-3 * /$ week & $94(45.4)$ & $10(18.2)$ & $5.1(2.42-10.75)$ & 0.004 \\
\hline $4 *$ and above & $30(14.5)$ & & - & - \\
\hline Total & $207(100.0)$ & $55(100.0)$ & - & - \\
\hline \multicolumn{5}{|c|}{ At $37 \mathrm{WA}$ and above } \\
\hline $1 * /$ week & $120(58.0)$ & $47(85.5)$ & $0.34(0.15-0.75)$ & 0.023 \\
\hline $2-3 * /$ week & $60(29.0)$ & $8(14.5)$ & $2.94(1.31-6.45)$ & 0.062 \\
\hline $4^{*}$ and above & $27(13.0)$ & & - & - \\
\hline Total & $207(100.0)$ & $55(100.0)$ & - & - \\
\hline
\end{tabular}

$\mathrm{FP}=$ favorable prejudice, $\mathrm{NFP}=$ non-favorable prejudice, $\mathrm{N}=$ total number, $\mathrm{n}=$ category number, $\%=$ percentage, $\mathrm{OR}=\mathrm{odd}$ ratio, $\mathrm{WA}=$ weeks of amenorrhea

Table 4: Distribution of the target population by mode of labor onset, use of oxytocin, cervical dilatation, fetal station at admission and state of membranes.

\begin{tabular}{|lllll|}
\hline Variables & FP $\mathbf{n = 2 0 7 , \mathbf { N } ( \% )}$ & NFP n=93, N (\%) & OR (95\% CI) & p value \\
\hline Mode of onset & & & & \\
\hline Spontaneous & $67(32.37)$ & $24(25.81)$ & $2.38(0.8-2.39)$ & 0.340 \\
\hline Artificial & $140(67.63)$ & $69(74.19)$ & & \\
\hline Use of oxyctocin & & & $2.03(1.08-3.83)$ & 0.029 \\
\hline Yes & $61(29.76)$ & $48(51.61)$ & $2.52(1.53-4.15)$ & 0.004 \\
\hline No & $144(70.24)$ & $45(48.39)$ & - & - \\
\hline
\end{tabular}

Continued. 


\begin{tabular}{|c|c|c|c|c|}
\hline Variables & FP $n=207, \mathbf{N}(\%)$ & NFP n=93, N (\%) & OR $(95 \% \mathrm{CI})$ & p value \\
\hline \multicolumn{5}{|c|}{$\begin{array}{l}\text { Cervical dilatation on } \\
\text { admission }\end{array}$} \\
\hline Latent phase & $78(37.68)$ & $34(36.56)$ & $1.05(0.63-1.74)$ & 0.883 \\
\hline Active phase & $129(62.32)$ & $59(63.44)$ & $0.95(0.57-1.7)$ & 0.910 \\
\hline \multicolumn{5}{|c|}{ Station at admission } \\
\hline$<2$ & $14(6.8)$ & - & $9(9.7)$ & 0.399 \\
\hline $2-4$ & $39(18.8)$ & - & $21(22.6)$ & 0.503 \\
\hline$\geq 4$ & $154(74.4)$ & - & $63(67.7)$ & 0.531 \\
\hline \multicolumn{5}{|c|}{ State of membranes } \\
\hline Intact & $146(70.53)$ & $72(77.42)$ & $0.7(0.4-1.24)$ & 0.517 \\
\hline Ruptured & $61(29.47)$ & $21(22.58)$ & $1.43(0.81-2.52)$ & 0.291 \\
\hline
\end{tabular}

$\mathrm{FP}=$ favorable prejudice, $\mathrm{NFP}=$ non favorable prejudice, $\mathrm{N}=$ total number, $\mathrm{n}=$ category number, $\%$ percentage, $\mathrm{OR}=$ odd ratio,

$\mathrm{CI}=$ confidence interval

Table 5: Distribution of the target population according to the delivery route.

\begin{tabular}{|lllll|} 
Route of delivery & FP $\mathbf{n = 2 0 7 , ~ N ~}(\%)$ & NFP n=93, N (\%) & OR (95\% CI) & P value \\
\hline Vaginal delivery & $105(50.72)$ & $47(50.54)$ & $1.01(0.62-1.65)$ & 0.983 \\
\hline Caesarean delivery & $102(49.28)$ & $46(49.46)$ & $0.99(0.61-1.62)$ & 0.983 \\
\hline
\end{tabular}

$\mathrm{FP}=$ favorable prejudice, $\mathrm{NFP}=$ non favorable prejudice, $\mathrm{N}=$ total number, $\mathrm{n}=$ category number, $\%$ percentage, $\mathrm{OR}=$ odd ratio,

$\mathrm{CI}=$ confidence interval

Table 6: Distribution of the target population according to obstetric trauma.

\begin{tabular}{|c|c|c|c|c|}
\hline Accouchement & FP n=207, N (\%) & NFP $n=93, \mathbf{N}(\%)$ & OR $(95 \% \mathrm{CI})$ & P value \\
\hline \multicolumn{5}{|l|}{ Perineal tear } \\
\hline Yes & $9(8.65)$ & $23(46.00)$ & $8.99(4.02-10.1)$ & 0.001 \\
\hline No & $95(91.34)$ & $27(54.00)$ & - & 1 \\
\hline \multicolumn{5}{|l|}{ Cervical tear } \\
\hline Yes & $1(0.96)$ & $8(16.32)$ & $5.44(2.44-8.73)$ & 0.0001 \\
\hline No & $103(99.03)$ & $41(83.67)$ & - & 1 \\
\hline \multicolumn{5}{|l|}{ Vaginal tear } \\
\hline Yes & $8(7.47)$ & $2(4.16)$ & $0.52(0.11-2.55)$ & 0.453 \\
\hline No & $99(92.52)$ & $46(95.83)$ & - & 1 \\
\hline \multicolumn{5}{|l|}{ Uterine rupture } \\
\hline Yes & $1(0.93)$ & $2(4.25)$ & $4.71(0.42-9.91)$ & 0.275 \\
\hline No & $106(99.06)$ & $45(95.74)$ & - & 1 \\
\hline \multicolumn{5}{|c|}{ Post partum haemorrhage } \\
\hline Yes & $2(1.94)$ & $12(25.53)$ & $5.77(0.51-9.23)$ & 0.117 \\
\hline No & $101(98.05)$ & $35(74.46)$ & - & 1 \\
\hline
\end{tabular}

$\mathrm{FP}=$ favorable prejudice, $\mathrm{NFP}=$ non favorable prejudice, $\mathrm{N}=$ total number, $\mathrm{n}=$ category number, $\%$ percentage, $\mathrm{OR}=$ odd ratio,

$\mathrm{CI}=$ confidence interval

Table 7: Distribution of the target population according to the characteristics of the newborn.

\begin{tabular}{|lllll|}
\hline Variables & FP $\mathbf{n = 2 0 7 , ~ N}(\%)$ & NFP $\mathbf{n = 9 3 , N}(\%)$ & OR (95\% CI) & P value \\
\hline Apgar at 1st min & & & & \\
\hline$<7$ & $57(27.54)$ & $34(36.56)$ & $0.62(0.37-1.05)$ & 0.189 \\
\hline$>7$ & $150(72.46)$ & $59(63.44)$ & $1.52(0.9-2.56)$ & 0.387 \\
\hline Apgar at 5th min & & & & \\
\hline$<7$ & $23(11.11)$ & $14(15.05)$ & $0.71(0.35-1.45)$ & 0.368 \\
\hline$>7$ & $184(88.89)$ & $79(84.95)$ & $1.42(0.69-2.91)$ & 0.736 \\
\hline
\end{tabular}

$\mathrm{FP}=$ favorable prejudice, $\mathrm{NFP}=$ non favorable prejudice, $\mathrm{N}=$ total number, $\mathrm{n}=$ category number, $\%$ percentage, $\mathrm{OR}=$ odd ratio,

$\mathrm{CI}=$ confidence interval 
Table 8: Distribution of the target population according to the fetal anomalies detected.

\begin{tabular}{|lllll|}
\hline Abnormalities discovered & FP $\mathbf{n = 2 0 7 ,} \mathbf{N}(\%)$ & NFP $\mathbf{n = 9 3 ,} \mathbf{N}(\%)$ & OR $(\mathbf{9 5 \%}$ CI $)$ & P value \\
\hline None & $156(75.36)$ & $70(75.27)$ & $0.79(0.3-2.09)$ & 0.884 \\
\hline Neonatal asphyxia & $17(8.21)$ & $6(6.45)$ & $1,25(0.39-4.02)$ & 0.644 \\
\hline Neonatal infection & $25(12.08)$ & $11(11.83)$ & $0.8(0.25-2.58)$ & 0.997 \\
\hline Others & $9(4.35)$ & $6(6.45)$ & $0.66(0.19-2.31)$ & 0.451 \\
\hline
\end{tabular}

$\mathrm{FP}=$ favorable prejudice, $\mathrm{NFP}=$ non favorable prejudice, $\mathrm{N}=$ total number, $\mathrm{n}=$ category number, $\%$ percentage, $\mathrm{OR}=$ odd ratio,

$\mathrm{CI}=$ confidence interval

Table 9: Distribution of the target population by fetal death.

\begin{tabular}{|lllll|}
\hline Fetal death & FP $n=207, \mathbf{N}(\%)$ & NFP $n=93, \mathbf{N}(\%)$ & OR (95\% CI) & P value \\
\hline Yes & $10(4.83)$ & $4(4.30)$ & $1.13(0.34-3.74)$ & 0.956 \\
\hline No & $197(95.17)$ & $89(95.70)$ & - & 1 \\
\hline
\end{tabular}

$\mathrm{FP}=$ favorable prejudice, $\mathrm{NFP}=$ non favorable prejudice, $\mathrm{N}=$ total number, $\mathrm{n}=$ category number, $\%$ percentage, $\mathrm{OR}=\mathrm{odd}$ ratio,

$\mathrm{CI}=$ confidence interval

\section{DISCUSSION}

Our comparative study sought to determine the benefit of sexual practice during pregnancy on childbirth.

\section{On the socio-demographic level}

Age

In our series, we had an average age of $27.27 \pm 6.28$ years with extremes of 15 and 45 without a significant difference for the age groups. Our findings are in harmony with those of the literature as reported by Kafei et al. ${ }^{6}$

\section{Type of occupation}

The predominant occupation was housewives (35.27\%) for the favourable prejudice group and school children $(33.33 \%)$ for the non-favourable prejudice group. There was no difference between the types of occupation among the respondents; our data are similar to those of Kafei et al.

\section{Sexual practice during pregnancy and coital frequency depending on the term}

Sexuality is intimate to ' $\mathrm{ME}$ ' and its questioning even in the context of safe confidentiality is not a comfortable exercise for everyone. Our results were mixed and varied according to the group surveyed and to some extent the term. However, a constant was observed in the group with NFP; because regardless of the term, the average was single weekly coitus despite bodily and physiological changes, the weight of traditions and taboos (nausea, vomiting, fear of abortion, harm to the foetus, and lack of interest in pregnant women). On the other hand, the group favourable to the sexual practice in pregnancy showed a regressive evolution of the weekly sexual frequency thus passing from 2-3 coitus at 28 SA to $36 \mathrm{SA}$ and 6 days to 1 weekly coitus at term $(48.3 \%$ of the women had 2 to 3 sexual intercourse/week before $28 \mathrm{SA} ; 45.4 \%$ between 28 SA and 36 SA and 6 days, and 29\% at term). Our findings are similar to the findings of Orji and Haywood. ${ }^{12,15}$

\section{Mode of induction of labour and use of oxytocin}

The trigger was artificial (balloon placement and detachment of the lower pole) in the majority of the cases in our series in the order of $69.6 \%$ (209 cases) with significant use of oxytocin in the group not favourable to sexual practice in pregnancy [OR: 2.52 (1.53-4.15); $\mathrm{p}=0.004]$ which therefore exposed more than twice to the use of oxytocin: our data are similar to the work of Foumane et al $(\mathrm{p}<0.05)$ who report reluctance to sexuality as a determinant of the use of oxytocin during labour. ${ }^{14}$ Added to these the work of Kavanagh et al on the effect of sexual intercourse on stimulation of the lower segment, the endogenous release of post orgasmic oxytocin, including the action of prostaglandins contained in the sperm ejaculate. ${ }^{16}$

\section{Delivery route}

Regardless of the group matched in our series, almost one in two pregnant women delivered by caesarean and the indications were invariably the same in both groups $(p=0.983)$. The findings of Tan et al go in the same direction. ${ }^{9}$

\section{Obstetric characteristics}

The African framework being potentially reproductive, more than $50 \%$ our series was made up of multi-gravid and multipara. This is contradictory to the study by Torkestani et al where the majority of women were nulliparous. ${ }^{7}$ The framework of his study seems to us to be the explanation.

\section{Maternal prognosis and state of the newborn at birth}

\section{Maternal complications}

Like Foumane et al, we did not find any statistical difference concerning the state of the membranes, the dilation, and the foetal station in the two groups. ${ }^{14}$ On the other hand, our findings relating to maternal complications are contrary to theirs because in our series, reluctance to 
sexual activity exposed more than eight times to perineal tears [OR: $8.99(4.02-10.1) ; \mathrm{p}=0.001]$ and more than five times to cervical tears [OR: $5.44(2.44-8.73) ; \mathrm{p}=0.0001]$; uterine rupture cases were found twice as often as in the opposite group and six times more cases of postpartum hemorrhage but without significant statistical impact.

In our opinion, this statistical gap probably stems from the differences observed in the two samples, but also from the subjective nature of some of the respondents' responses. But beyond the thesis and antithesis sequence of this analysis, it should be recalled that the data in the literature on the inappropriate use of oxytocin are the same as our findings and the latter cannot be a relevant argument. Unless there is a subsequent multi-centre cohort study better developed on this theme in order to identify certain elements of statistical confusion.

\section{Apgar score}

We found no significant statistical difference in foetal wellbeing in the two groups (Apgar score, malformation and death). Our findings are similar to that of Tan et al. ${ }^{9}$ This suggests that sexual activity has no effect on the state of the new-born.

\section{Limitations of our study}

The delicacy of the subject under study associated with the weights of our cultures constituted a handicap both in the enrollment and in the reliability of essentially declarative data.

A strong subjectivity emerges from it and therefore does not allow analyzes or relevant conclusions, because depending on the psychological profile, some respondents could reduce or increase the frequency of their weekly coitus and thus constitute significant biases.

\section{CONCLUSION}

At the end of our work we formulate the hypothesis that the sexual practice in pregnancy would protect from excessive use of oxytocin, cervical and perineal tears, postpartum haemorrhages and uterine ruptures. While promoting the sexual practice in pregnancy for more marital harmony, our findings however require subsequent multi-centre studies of cohort follow-up in order to discriminate certain variables of statistical confusion because the inappropriate use of oxytocin is known to be the cause of pelvic tears, postpartum haemorrhages by consecutive uterine atony rapid labour, foetal distress, without forgetting the practical profile of the birth attendant.

\section{ACKNOWLEDGMENTS}

The authors thank the Laquintinie hospital administration and the maternity staff for their multifaceted support during this study.
Funding: No funding sources

Conflict of interest: None declared

Ethical approval: The study was approved by the Institutional Ethics Committee

\section{REFERENCES}

1. Grossesse JW. In: Larousse. Le Larousse médical. 5th ed. Paris; 2012: 426.

2. Babazadeh R, Mirzaii K, Masomi Z. Changes in sexual desire and activity during pregnancy among women in Shahroud, Iran. Int $\mathbf{J}$ Gynecol Obstet. 2013;120(1):82-4.

3. Doucet-Jeffray N, Miton-Conrath S, Le Mauff P, Senand R. Quelle sexualité pour les hommes pendant la grossesse. Rev Exerc. 2004;71:111-9.

4. Kavanagh J, Kelly AJ, Thomas J. Breast stimulation for cervical ripening and induction of labour. Cochrane Database Syst Rev. 2001:4.

5. Ganem M. La sexualité du couple pendant la grossesse. Paris: Filipacchi. 1992. Available at: https://www.google.com/search?sxsrf=ALeKk009v8 68Wd-zK2SnwukLvHwFTecy9w\%3A15994598588 $08 \&$ source $=$ hp\&ei $=$ EtJVX6aXL5Kwa5rNuLAC\&q= Ganem+M.+La+sexualit\%C3\%A9+du+couple+pend ant+la+grossesse.+Paris+\%3A+Filipacchi+\%3B1992 \&oq=Ganem + M.+La+sexualit\%C3\%A9+du+couple +pendant+la+grossesse.+Paris+\%3A+Filipacchi $+\% 3$ B1992\&gs_lcp=CgZwc3ktYWIQDFDuH1juH2DR M2gAcAB4AIAB7gWIAe4FkgEDNi0xmAEAoAE CoAEBqgEHZ3dzLXdpeg\&sclient=psy-ab\&ved=0a hUKEwim6NultNbrAhUS2BoKHZomDiYQ4dUDC Ao. Accessed on 07 September 2020.

6. Atrian MK, Sadat Z, Bidgoly MR, Abbaszadeh F, Jafarabadi MA. The association of sexual intercourse during pregnancy with labor onset. Iran Red Crescent Med J. 2014;17(1):7.

7. Torkestani F, Hadavand SH, Khodashenase Z, Besharat S, Davati A, Karimi Z, et al. Frequency and perception of sexual activity during pregnancy in Iranian couples. Int J Fertil Steril. 2012;6(2):107.

8. Chhabra S, Verma P. Sexual activity and onset of preterm labour. Indian J Matern Child Health Off Publ Indian Matern Child Health Assoc. 1991;2(2):54.

9. Tan PC, Andi A, Azmi N, Noraihan MN. Effect of coitus at term on length of gestation, induction of labor, and mode of delivery. Obstet Gynecol. 2006;108(1):134-40.

10. Bartoli L. Venir au monde : les rites de l'enfantement sur les cinq continents. Paris : Payot \& Rivages. 2007. Available at: https://www.google.com/search?sxsrf= ALeKk00SOgD0EpeN8YwLVmaSsgLvqAAulg:159 9461098842\&q=Bartoli+L.+Venir+au+monde+:+les + rites+de+1\%27enfantement+sur+les+cinq+continen ts.+Paris+:+Payot+\%26+Rivages+;+2007\&spell=1\& sa=X\&ved=2ahUKEwjflYP1uNbrAhXCA2MBHYY SC5kQBSgAegQICxAm\&biw=1280\&bih=657. Accessed on: 07 September 2020.

11. Sangaré I, Sirima C, Bamba S, Zida A, Cissé M, Bazié WW, et al. Prevalence of vulvovaginal candidiasis in 
pregnancy at three health centers in Burkina Faso. J Mycol Medicale. 2018;28(1):186-92.

12. Orji EO, Ogunlola IO, Fasubaa OB. Sexuality among pregnant women in South West Nigeria. J Obstet Gynaecol. 2002;22(2):166-8.

13. Adinma JIB. Sexuality in Nigerian pregnant women: perceptions and practice. Aust N Z J Obstet Gynaecol. 1995;35(3):290-3.

14. Foumane P, Mboudou ET, Sama JD, Baba S, Enama Mbatsogo BA, Ngwana L. Sexual activity during pregnancy and prognosis of labor in Cameroonian women: a cohort study. J Matern Fetal Neonatal Med. 2014;27(13):1305-8.
15. Brown HL, McDaniel ML. A review of the implications and impact of pregnancy on sexual function. Curr Sex Health Rep. 2008;5(1):51-5.

16. Kavanagh J, Kelly AJ, Thomas J. Sexual intercourse for cervical ripening and induction of labour. Cochrane Database Syst Rev. 2001;(2).

Cite this article as: Essome H, Egbe TO, Nana TN, Mve VK, Boten M, Tocki GT, et al. Benefits of sexual practice during pregnancy: myth or reality? Comparative study and outcome of childbirth in Douala (Cameroon). Int J Reprod Contracept Obstet Gynecol 2020;9:3944-52. 